\title{
Determining the Optimal Scalar Intensity Measure of Floor Communication Towers
}

\author{
Bo Li $\left(\mathbb{D},{ }^{1,2}\right.$ Qinghui Lai, ${ }^{3}$ Endong Guo, ${ }^{1}$ Chenxi Mao, ${ }^{1}$ and Xiaofei $\mathrm{Li}^{2}$ \\ ${ }^{1}$ Key Laboratory of Earthquake Engineering and Engineering Vibration, Institute of Engineering Mechanics, \\ China Earthquake Administration, Harbin 150080, China \\ ${ }^{2}$ School of Architecture Engineering, Binzhou University, Binzhou 256600, China \\ ${ }^{3}$ State Key Laboratory of Precision Blasting, Jianghan University, Wuhan 430056, China \\ Correspondence should be addressed to Bo Li; libo20070025@126.com
}

Received 16 November 2021; Revised 12 January 2022; Accepted 21 January 2022; Published 23 February 2022

Academic Editor: Luigi Di Sarno

Copyright (C) 2022 Bo Li et al. This is an open access article distributed under the Creative Commons Attribution License, which permits unrestricted use, distribution, and reproduction in any medium, provided the original work is properly cited.

\begin{abstract}
Various structural types and ground motion characteristics lead to distinct intensity measures of structural seismic performance. For the lattice high-rise steel structure of communication towers, determining the intensity measures to adjust ground motion is critical. Additionally, a crucial problem is whether the ground motion intensity parameters of pulse-like ground motion and ordinary ground motion are consistent. In this study, a standard floor four-leg angle steeled communication tower was considered the study object, and 50 pulse-like ground motions and 50 ordinary ground motions were identified to form a pulse-like ground motion set and ordinary ground motion set, respectively. For comparative analyses, 15 ground motion parameters, including amplitude, spectrum, duration, and energy parameters, were selected. The results revealed that for the lattice towers, such as communication tower, under the action of pulse-like ground motion or ordinary ground motion, efficiency, practicability, and sufficiency should be considered. Furthermore, the most suitable intensity measure was the spectral acceleration corresponding to the natural period of the tower. This study provides a basis for selecting the ground motion for dynamic time history analysis of the lattice steel tower.
\end{abstract}

\section{Introduction}

With the continuous development of $5 \mathrm{G}$ communication technology and Internet, portable communication network services and applications, such as smartphone payment, online office and teaching, and webcast, have become an indispensable part of people's daily lives. As the main carrier of the communication antenna, the operation of communication towers is primarily associated with the smoothness of the communication system. Conventionally, the design of communication towers is considered for the perspective of its wind resistance performance [1-3]. However, China's Wenchuan earthquake, Yushu earthquake, and Japan's '311' earthquake and other earthquake damage investigations have revealed that in the event of an earthquake, damage to communication towers results in the suspension of communication with the outside world in some areas $[4,5]$. In such scenarios, rescue operations cannot be performed effectively, causing considerable casualties and loss of property.

Typically, dynamic time history analysis is used to analyse the seismic performance of structures. The results revealed that the ground motion parameters (intensity measures, $\mathrm{IM}_{\mathrm{i}}$ ) suitable for the study of structural seismic performance differed with the type of structures and ground motion characteristics. For lattice towers, including transmission towers and communication towers, currently, the seismic intensity measures identified by dynamic time history analysis or amplitude modulated ground motion predominantly involve peak acceleration (PGA) $[6,7]$, peak velocity (PGV) $[8]$, spectral acceleration $\mathrm{Sa}\left(T_{1}\right)$ corresponding to the natural period of the structure $[9,10]$ and the ratio of peak velocity to peak acceleration (V/A) [11]. In theoretical research and 
engineering practice, ground motion intensity is typically quantitatively characterised by ground motion parameters, in which scalar parameters predominantly include amplitude parameters, spectrum parameters, duration parameters, and energy parameters [12-14]. The use of appropriate intensity measures to select and adjust natural ground motion and the selection of appropriate engineering demand parameters (EDP) to evaluate structural damage are conducive to reducing the discrete type of structural dynamic time history analysis results and improving calculation efficiency. Therefore, the selection of reliable intensity measures is critical for structural dynamic response analysis. Compared with ordinary ground motion, pulse-like earthquakes typically exhibit a wide response spectrum sensitive area. Because earthquakes produce high-energy input to the structure in a short time, this ground motion typically causes considerable damage to the engineering structure. However, for the lattice highrise steel structure of the communication tower, determining the type of intensity measure that is the most effective to specify and adjust ground motion is critical. Currently, limited studies have been conducted to determine if the most effective parameters of pulse-like ground motion and ordinary ground motion are consistent.

In this study, a standard floor four-leg angle steeled communication tower was considered the research object, 50 pulse-like ground motions and 50 ordinary ground motions were gathered from PEER ground motion data centre to form the pulse and ordinary ground motion sets, respectively. A total of 15 ground motion parameters, including amplitude parameters, spectrum parameters, duration parameters, and energy parameters, were selected for comparative analysis. Considering the uncertainty of the input ground motion, the optimal intensity measures under pulse-like ground motion and ordinary earthquake action were selected from the perspectives of efficiency, practicability, and sufficiency. This study provides a basis of selecting ground motion for dynamic time history analysis of lattice steel tower.

\section{Ground Motion Records}

In the process of dynamic time history analysis of earthquakes, accurate evaluation of ground motion is critical for determining whether the analysis results are effective. Pulselike ground motion closely related to the relative position between site and seismic fault has attracted considerable attention in structural engineering. Because its main energy occurs in a concentrated time or frequency domain, pulselike ground motion is generally recognised as the key factor causing severe damage to all engineering structures.

By using the simplified and efficient method proposed by Zhai [15] for quantitatively identifying pulse-like ground motions, 50 pulse-like and 50 ordinary ground motions were obtained from the PEER ground motion database to form pulse-like and ordinary ground motion sets, and the cloud analysis method was employed to analyse the structure $[16,17]$. The established ground motions are listed in Table 1.

\section{Intensity Measures}

A reasonable intensity measure is a critical basis for evaluating the structural response and recoverable ability of the structural seismic function. This measure should reflect the structural seismic response index or damage indexes. The selection of intensity measures should be comprehensive and cover three elements of ground motion, namely amplitude parameters, spectrum parameters, and duration parameters, as well as energy parameters [12-14, 18]. The selection of intensity measures should specify representative ground motion parameters with clear physical meaning, wide application range, and high frequency in seismic engineering. The representative intensity measures discussed in this study are presented in Table 2 . The intensity measures considered in this study did not include vector parameters.

\section{Description of the Model}

4.1. Overview of the Selected Tower and Finite Element Model. To analyse object representative, a $50 \mathrm{~m}$ high falling fourlegged steel tower was selected as the structural prototype of the standard Atlas of communication tower formulated by China Tower Co. Ltd. General finite element software ABAQUS was used to construct the finite element model. Q345 and Q235 section steel was used for main material and inclined material, respectively, which were simulated by the beam element. The damping ratio is $2 \%$. As a high-rise structure, the communication tower is highly influenced by the p-delta effect. Therefore, initial defects were introduced in the analysis process. Considering the influence of bending and shear deformation of members, the contribution to structural stiffness to natural vibration period and frequency was consistent with those in practice, and the geometric nonlinearity of the structure was considered. Because of the material nonlinearity of structural steel, pursuant to the ideal elastic-plastic assumption, von Mises criterion was implemented as the material yield criterion, and the double broken line constitutive model was adopted as the material constitutive model. The mechanical parameters are presented in Table 3. The antenna platform at the top of the tower, lightning rod, bolts, and ladders at each section were applied as additional loads at the horizontal nodes of each section. The sketch of the prototype structure is displayed in Figure 1, and the components size and the additional mass of the tower are displayed in Table 4. The bottom of the tower was absolutely consolidated. According to the modal analysis, the mass participation ratios of the first three modes are $37.2 \%, 34.4 \%$, and $20.5 \%$, totally $92.1 \%$. The first three mode shapes are shown in Figure 2.

4.2. Model Verification. The rationality of the finite element model is directly relevant to the reliability of the analysis results. To verify the rationality of the aforementioned model, a $50-\mathrm{m}$ four-legged steel tower was designed conforming to the standard Atlas of communication tower in Harbin, Heilongjiang Province, for the frequency test. A three-way acceleration sensor was placed on the top 
TABLE 1: Selected ground motions.

\begin{tabular}{|c|c|c|c|c|c|c|}
\hline \multicolumn{7}{|c|}{ (a) Pulse-like ground motions } \\
\hline Seq. & RSN & Event & Year & Station & M & EpiD $(\mathrm{km})$ \\
\hline 1 & 77 & San fernando & 1971 & Pacoima dam & 6.61 & 11.87 \\
\hline 2 & 184 & Imperial Valley-06 & 1979 & El centro & 6.53 & 27.23 \\
\hline 3 & 250 & Mammoth Lakes-06 & 1980 & Long valley dam & 5.94 & 14.04 \\
\hline 4 & 296 & Irpinia, Italy-02 & 1980 & Bagnoli irpinio & 6.2 & 22.29 \\
\hline 5 & 503 & Taiwan SMART1(40) & 1986 & SMART1 C00 & 6.32 & 68.18 \\
\hline 6 & 506 & Taiwan SMART1(40) & 1986 & SMART1 I07 & 6.32 & 67.98 \\
\hline 7 & 540 & N. Palm springs & 1986 & Whitewater & 6.06 & 4.24 \\
\hline 8 & 614 & Whittier Narrows-01 & 1987 & Downey-birchdale & 5.99 & 15.29 \\
\hline 9 & 645 & Whittier Narrows-01 & 1987 & LB-orange ave & 5.99 & 20.68 \\
\hline 10 & 732 & Loma Prieta & 1989 & APEEL 2 & 6.93 & 63.49 \\
\hline 11 & 738 & Loma prieta & 1989 & Alameda naval air & 6.93 & 90.77 \\
\hline 12 & 764 & Loma prieta & 1989 & Gilroy & 6.93 & 28.11 \\
\hline 13 & 779 & Loma prieta & 1989 & LGPC & 6.93 & 18.46 \\
\hline 14 & 784 & Loma prieta & 1989 & Oakland-title & 6.93 & 91.68 \\
\hline 15 & 787 & Loma prieta & 1989 & Palo alto-SLAC lab & 6.93 & 51.2 \\
\hline 16 & 802 & Loma prieta & 1989 & Saratoga-aloha ave & 6.93 & 27.23 \\
\hline 17 & 803 & Loma prieta & 1989 & Saratoga $-W$ valley & 6.93 & 27.05 \\
\hline 18 & 805 & Loma prieta & 1989 & Stanford park. Garage & 6.93 & 18.60 \\
\hline 19 & 808 & Loma prieta & 1989 & Treasure island & 6.93 & 97.43 \\
\hline 20 & 821 & Erzican, Turkey & 1992 & Erzincan & 6.69 & 8.97 \\
\hline 21 & 879 & Landers & 1992 & Lucerne & 7.28 & 44.02 \\
\hline 22 & 900 & Landers & 1992 & Yermo fire station & 7.28 & 85.99 \\
\hline 23 & 953 & Northridge-01 & 1994 & Beverly hills & 6.69 & 13.39 \\
\hline 24 & 960 & Northridge-01 & 1994 & Canyon country & 6.69 & 26.49 \\
\hline 25 & 963 & Northridge-01 & 1994 & Castaic & 6.69 & 40.68 \\
\hline 26 & 1003 & Northridge-01 & 1994 & LA—saturn st & 6.69 & 25.52 \\
\hline 27 & 1004 & Northridge-01 & 1994 & LA-sepulveda & 6.69 & 8.48 \\
\hline 28 & 1007 & Northridge-01 & 1994 & Los angeles & 6.69 & 36.47 \\
\hline 29 & 1013 & Northridge- 01 & 1994 & LA dam & 6.69 & 11.79 \\
\hline 30 & 1045 & Northridge-01 & 1994 & Newhall & 6.69 & 21.55 \\
\hline 31 & 1050 & Northridge-01 & 1994 & Pacoima Dam & 6.69 & 20.36 \\
\hline 32 & 1054 & Northridge-01 & 1994 & Pardee-SCE & 6.69 & 25.65 \\
\hline 33 & 1081 & Northridge-01 & 1994 & Stone canyon & 6.69 & 21.75 \\
\hline 34 & 1084 & Northridge-01 & 1994 & Converter sta & 6.69 & 13.11 \\
\hline 35 & 1085 & Northridge-01 & 1994 & Converter sta east & 6.69 & 13.60 \\
\hline 36 & 1106 & Kobe, Japan & 1995 & KJMA & 6.90 & 18.27 \\
\hline 37 & 1116 & Kobe, Japan & 1995 & Shin-osaka & 6.90 & 45.97 \\
\hline 38 & 1119 & Kobe, Japan & 1995 & Takarazuka & 6.90 & 38.60 \\
\hline 39 & 1120 & Kobe, Japan & 1995 & Takatori & 6.90 & 13.12 \\
\hline 40 & 1148 & Kocaeli, Turkey & 1999 & Arcelik & 7.51 & 53.68 \\
\hline 41 & 1170 & Kocaeli, Turkey & 1999 & Sakarya & 7.51 & 90.66 \\
\hline 42 & 1176 & Kocaeli, Turkey & 1999 & Yarimca & 7.51 & 19.30 \\
\hline 43 & 1182 & Chi-chi, Taiwan & 1999 & CHY006 & 7.62 & 40.47 \\
\hline 44 & 1197 & Chi-chi, Taiwan & 1999 & CHY028 & 7.62 & 32.67 \\
\hline 45 & 1198 & Chi-chi, Taiwan & 1999 & CHY029 & 7.62 & 39.70 \\
\hline 46 & 1231 & Chi-chi, Taiwan & 1999 & CHY080 & 7.62 & 31.65 \\
\hline 47 & 1244 & Chi-chi, Taiwan & 1999 & CHY101 & 7.62 & 31.96 \\
\hline 48 & 1504 & Chi-chi, Taiwan & 1999 & TCU067 & 7.62 & 28.70 \\
\hline 49 & 1550 & Chi-chi, Taiwan & 1999 & TCU136 & 7.62 & 48.75 \\
\hline 50 & 1602 & Duzce, Turkey & 1999 & Bolu & 7.14 & 41.27 \\
\hline \multicolumn{7}{|c|}{ (b) Ordinary ground motions } \\
\hline Seq. & RSN & Event & Year & Station & $\mathrm{M}$ & EpiD $(\mathrm{km})$ \\
\hline 1 & 432 & Taiwan SMART1(25) & 1983 & SMART1 O01 & 6.50 & 100.64 \\
\hline 2 & 1036 & Northridge- 01 & 1994 & Mojave-hwys 14 & 6.69 & 102.24 \\
\hline 3 & 1163 & Northridge-01 & 1994 & Rinaldi receiving sta & 7.51 & 101.86 \\
\hline 4 & 1217 & Chi-chi, Taiwan & 1999 & CHY060 & 7.62 & 91.08 \\
\hline 5 & 1471 & Chi-chi, Taiwan & 1999 & TCU015 & 7.62 & 101.62 \\
\hline 6 & 1747 & Little skull mtn, NV & 1992 & Station \#8 & 5.65 & 99.66 \\
\hline 7 & 1789 & Hector mine & 1999 & Hesperia -4 th and palm & 7.13 & 98.53 \\
\hline
\end{tabular}


TABle 1: Continued.

\begin{tabular}{|c|c|c|c|c|c|c|}
\hline \multicolumn{7}{|c|}{ (a) Pulse-like ground motions } \\
\hline Seq. & RSN & Event & Year & Station & M & EpiD $(\mathrm{km})$ \\
\hline 8 & 1929 & Anza-02 & 2001 & Corona & 4.92 & 101.56 \\
\hline 9 & 1969 & Anza-02 & 2001 & Riverside & 4.92 & 101.05 \\
\hline 10 & 1973 & Anza-02 & 2001 & Riverside Airport & 4.92 & 99.31 \\
\hline 11 & 1995 & Gulf of California & 2001 & El Centro Array \#11 & 5.7 & 102.56 \\
\hline 12 & 2178 & Chi-chi, Taiwan-02 & 1999 & CHY054 & 6.20 & 100.24 \\
\hline 13 & 2833 & Chi-chi, Taiwan-02 & 1999 & KAU078 & 6.20 & 100.58 \\
\hline 14 & 2959 & Chi-chi, Taiwan-05 & 1999 & CHY055 & 6.20 & 102.15 \\
\hline 15 & 2961 & Chi-chi, Taiwan-05 & 1999 & CHY057 & 6.20 & 100.40 \\
\hline 16 & 2965 & Chi-chi, Taiwan-05 & 1999 & CHY061 & 6.20 & 100.17 \\
\hline 17 & 2966 & Chi-chi, Taiwan-05 & 1999 & CHY062 & 6.20 & 100.04 \\
\hline 18 & 2988 & Chi-chi, Taiwan-05 & 1999 & CHY100 & 6.20 & 99.39 \\
\hline 19 & 2990 & Chi-chi, Taiwan-05 & 1999 & CHY107 & 6.20 & 98.67 \\
\hline 20 & 3072 & Chi-chi, Taiwan-05 & 1999 & ILA062 & 6.20 & 102.97 \\
\hline 21 & 3073 & Chi-Chi, Taiwan-05 & 1999 & ILA064 & 6.20 & 102.68 \\
\hline 22 & 3074 & Chi-chi, Taiwan-05 & 1999 & ILA066 & 6.20 & 99.75 \\
\hline 23 & 3165 & Chi-chi, Taiwan-05 & 1999 & TCU033 & 6.20 & 99.89 \\
\hline 24 & 3194 & Chi-chi, Taiwan-05 & 1999 & TCU085 & 6.20 & 100.36 \\
\hline 25 & 3280 & Chi-chi, Taiwan-06 & 1999 & CHY044 & 6.30 & 101.89 \\
\hline 26 & 3286 & Chi-chi, Taiwan-06 & 1999 & CHY055 & 6.30 & 100.75 \\
\hline 27 & 3287 & Chi-chi, Taiwan-06 & 1999 & CHY057 & 6.30 & 100.89 \\
\hline 28 & 3291 & Chi-chi, Taiwan-06 & 1999 & CHY061 & 6.30 & 101.92 \\
\hline 29 & 3292 & Chi-chi, Taiwan-06 & 1999 & CHY062 & 6.30 & 101.03 \\
\hline 30 & 3316 & Chi-chi, Taiwan-06 & 1999 & CHY100 & 6.30 & 98.81 \\
\hline 31 & 3392 & Chi-Chi, Taiwan-06 & 1999 & ILA066 & 6.30 & 100.46 \\
\hline 32 & 3484 & Chi-chi, Taiwan-06 & 1999 & TCU094 & 6.30 & 100.17 \\
\hline 33 & 3531 & Chi-chi, Taiwan-06 & 1999 & TTN024 & 6.30 & 100.37 \\
\hline 34 & 3584 & Taiwan SMART1(25) & 1983 & SMART1 I10 & 6.50 & 99.30 \\
\hline 35 & 3585 & Taiwan SMART1(25) & 1983 & SMART1 I11 & 6.50 & 99.33 \\
\hline 36 & 3586 & Taiwan SMART1(25) & 1983 & SMART1 I12 & 6.50 & 99.36 \\
\hline 37 & 3587 & Taiwan SMART1(25) & 1983 & SMART1 M02 & 6.50 & 99.47 \\
\hline 38 & 3590 & Taiwan SMART1(25) & 1983 & SMART1 M05 & 6.50 & 98.24 \\
\hline 39 & 3601 & Taiwan SMART1(25) & 1983 & SMART1 O09 & 6.50 & 99.68 \\
\hline 40 & 3783 & Hector mine & 1999 & Beaumont & 7.13 & 98.80 \\
\hline 41 & 3883 & Tottori, Japan & 2000 & HRS017 & 6.61 & 100.23 \\
\hline 42 & 3917 & Tottori, Japan & 2000 & OKY014 & 6.61 & 100.93 \\
\hline 43 & 3946 & Tottori, Japan & 2000 & SMN018 & 6.61 & 102.27 \\
\hline 44 & 3957 & Tottori, Japan & 2000 & SMNH13 & 6.61 & 99.33 \\
\hline 45 & 4152 & Niigata, Japan & 2004 & FKS021 & 6.63 & 98.33 \\
\hline 46 & 4154 & Niigata, Japan & 2004 & FKS023 & 6.63 & 98.25 \\
\hline 47 & 4240 & Niigata, Japan & 2004 & TCG009 & 6.63 & 101.23 \\
\hline 48 & 4244 & Niigata, Japan & 2004 & TCGH09 & 6.63 & 101.85 \\
\hline 49 & 5001 & Chuetsu-oki, Japan & 2007 & FKSH01 & 6.80 & 99.92 \\
\hline 50 & 5060 & Chuetsu-oki, Japan & 2007 & GNM001 & 6.80 & 100.83 \\
\hline
\end{tabular}

platform of the tower with a height of $48.2 \mathrm{~m}$ (Figure 3). Pile foundations were used for the tower, and the soil was hard, which can be approximately equivalent to the fixed constraint at the bottom. According to the conversion relationship between the fundamental frequency and the first period, the natural periods in $X$ and $Y$ directions of the actual structure and finite element model were derived, as presented in Table 5. The natural period difference between the finite element model and the prototype structure of both directions was less than $15 \%$, which revealed the finite element model of communication tower based on ABAQUS to be acceptable and reliable.
4.3. Structural Response. The function of the communication tower is to support the transmission antenna to receive and transmit signals in an area. The dynamic response to the tower under an earthquake is principally monitored by using the maximum roof drift (MRD) of the tower top relative to the tower bottom. Furthermore, as a lattice high-rise steel structure, the communication tower exhibits a large acceleration amplification effect at the top of the tower under the action of a horizontal earthquake, whereas the communication antenna and the tower top platform are mainly linked by bolts. The amplified acceleration at the top of the tower exhibits a large dynamic response to the connected bolts. 
TABLE 2: IMs considered in this study.

\begin{tabular}{|c|c|c|c|}
\hline \multirow{2}{*}{ Class } & \multicolumn{2}{|r|}{ IMi } & \multirow{2}{*}{ Expression } \\
\hline & Notation & Definition/references & \\
\hline \multirow{4}{*}{ Amplitude parameters } & PGA & Peak ground acceleration & $\mathrm{PGA}=\max |a(t)|$ \\
\hline & PGV & Peak ground velocity & $\mathrm{PGV}=\max |\nu(t)|$ \\
\hline & PGD & Peak ground displacement & $\mathrm{PGD}=\max |d(t)|$ \\
\hline & V/A & Ratio of peak velocity to peak acceleration & PGV/PGA \\
\hline \multirow{4}{*}{ Spectrum parameters } & EPA & Effective peak acceleration & $\mathrm{EPA}=S_{a} / 2.5$ \\
\hline & EPV & Effective peak velocity & $\mathrm{EPV}=S_{v} / 2.5$ \\
\hline & SI & Housner spectral intensity & $S_{I}(\zeta)=\int_{01}^{2.5} S_{V}(\zeta, T) \mathrm{dt}$ \\
\hline & $\mathrm{Sa}\left(T_{1}\right)$ & Spectral acceleration at the fundamental period & $S_{\mathrm{a}}\left(T_{1}, \xi\right)$ \\
\hline Duration parameters & $\mathrm{U}_{\mathrm{du}}$ & Consistent duration & $U_{\mathrm{du}}=\sum_{i} t_{i}$ \\
\hline \multirow{5}{*}{ Energy parameters } & $\frac{\mathrm{S}_{\mathrm{du}}}{\mathrm{CAV}}$ & $\begin{array}{c}\text { Duration of strong ground motion } \\
\text { Cumulative absolute velocity }\end{array}$ & $\begin{array}{c}S_{90}=t_{95}-t_{5} \\
\mathrm{CAV}=\int^{t_{\max }}|a(t)| d(t)\end{array}$ \\
\hline & $\mathrm{CAV}_{S}$ & Standard cumulative absolute velocity & $\mathrm{CAV}_{S}=\sum_{i} \int_{t}^{a_{i}+1} W_{i}|a(t)| d(t)$ \\
\hline & MIV & Maximum incremental speed & $\mathrm{MIV}=\max \left(\int_{\theta}^{t_{\max }} a(t) d(t)\right)$ \\
\hline & MID & Maximum incremental displacement & $\mathrm{MID}=\max \left(\int_{0}^{\max } v(t) d(t)\right)$ \\
\hline & AI & Arias intensity & $I_{A}=\pi / 2 g \int_{0}^{t} a^{2}(t) \mathrm{dt}$ \\
\hline
\end{tabular}

TABle 3: Mechanical properties of Q345 and Q235.

\begin{tabular}{lccccc}
\hline Material & Yield stress $(\mathrm{Pa})$ & Strain-hardening ratio & Young' modulus $(\mathrm{Pa})$ & Poisson's ratio & Density $\left(\mathrm{kg} / \mathrm{m}^{3}\right)$ \\
\hline Q345 & $3.45 \mathrm{E}+8$ & 1.37 & $2.06 \mathrm{E}+11$ & 0.3 & 7850 \\
Q235 & $2.35 \mathrm{E}+8$ & & $2.06 \mathrm{E}+11$ & 0.3 & 7850 \\
\hline
\end{tabular}

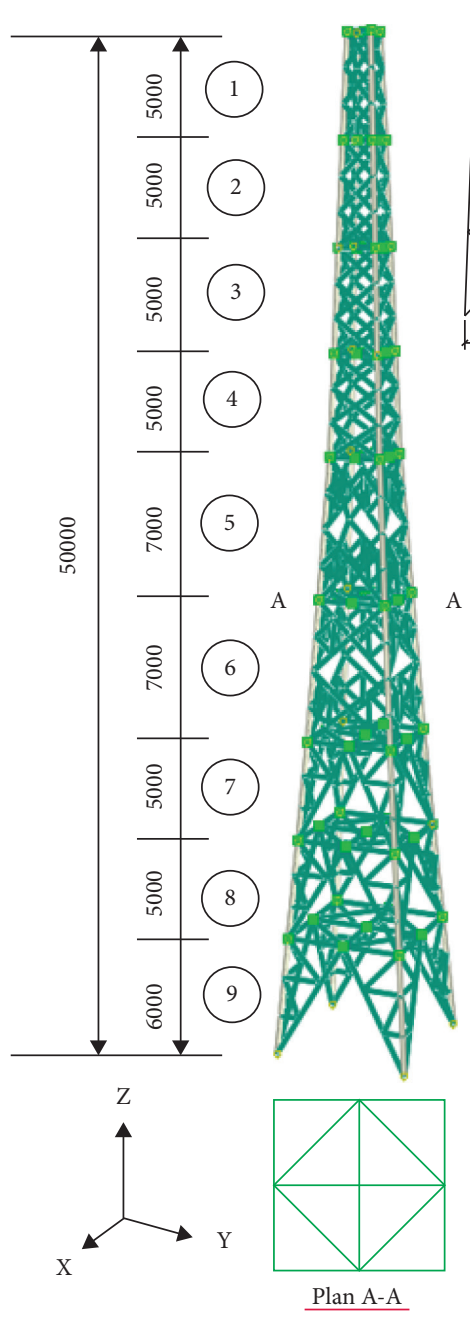

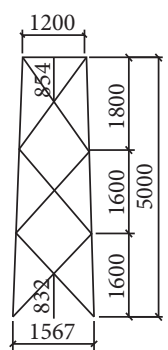

(1)

A

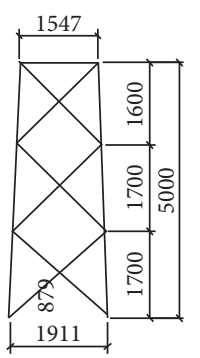

(2)

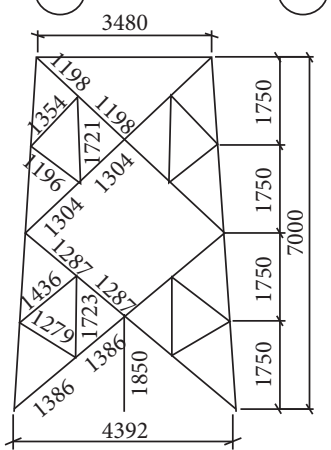

(6)

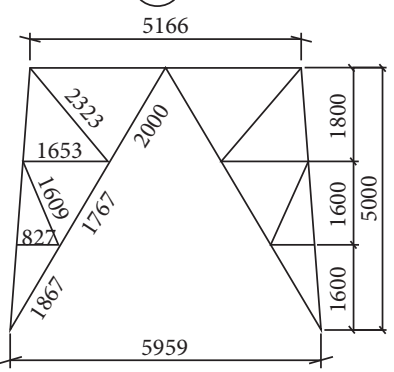

(8)

(3)

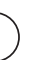

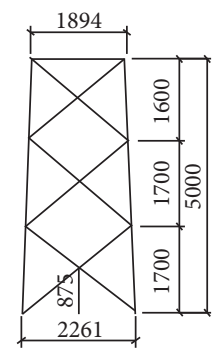

4

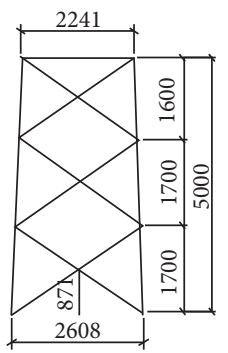

(4)
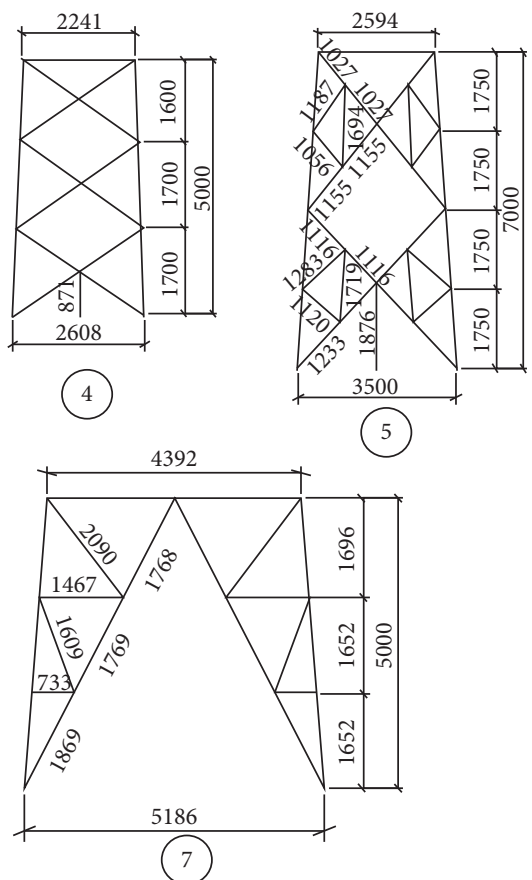

(5)

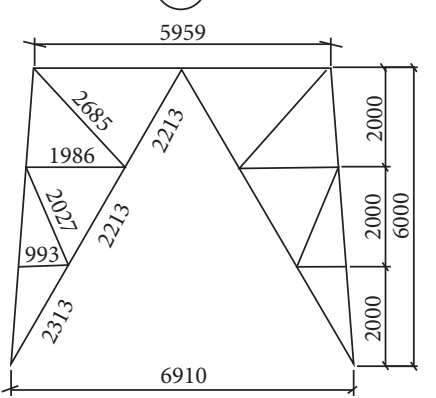

(9)

FIGURE 1: Sketch of the prototype Structure (unit: $\mathrm{mm}$ ). 
TABle 4: Components size.

\begin{tabular}{|c|c|c|}
\hline Legs (unit: $\mathrm{mm}$ ) & Braces (unit: mm) & Added mass $(\mathrm{kg})$ \\
\hline L80 $\times 6$ & L50 $\times 5$ & 1003.3 \\
\hline $\mathrm{L} 100 \times 8$ & L56 x 5 & 971.6 \\
\hline $\mathrm{L} 125 \times 10$ & L63 $\times 5$ & 1126.7 \\
\hline $\mathrm{L} 140 \times 12$ & L63 $\times 5$ & 1247.8 \\
\hline $\mathrm{L} 160 \times 14$ & L63 $\times 5$ & 273.4 \\
\hline $\mathrm{L} 180 \times 16$ & $\mathrm{~L} 70 \times 5$ & 290.6 \\
\hline $\mathrm{L} 180 \times 16$ & L80 $\times 6$ & 270.3 \\
\hline $\mathrm{L} 200 \times 16$ & L90 x 7 & 280.5 \\
\hline $\mathrm{L} 200 \times 18$ & $\mathrm{~L} 100 \times 7$ & 295.6 \\
\hline
\end{tabular}

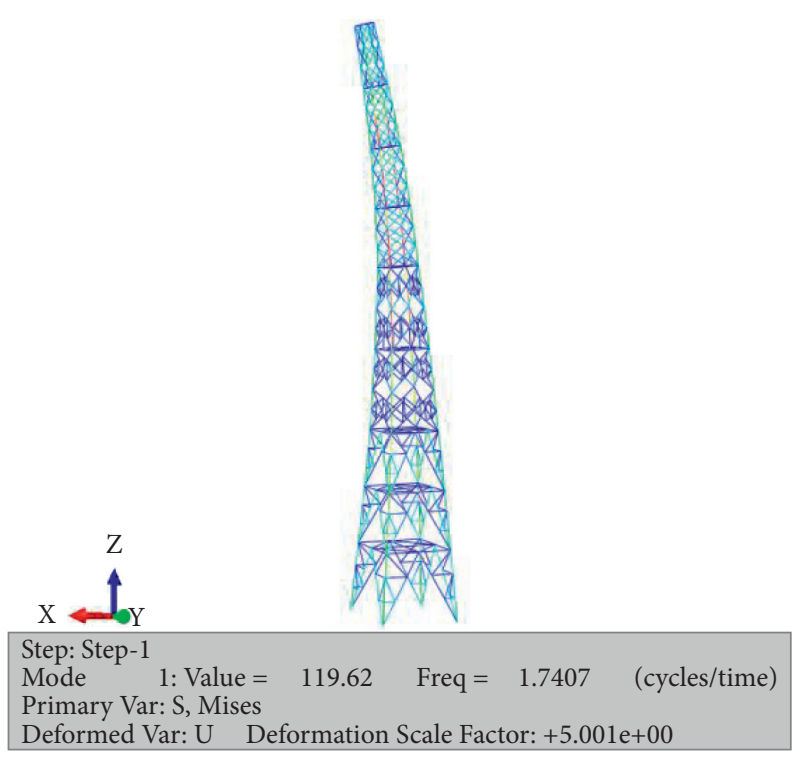

(a)

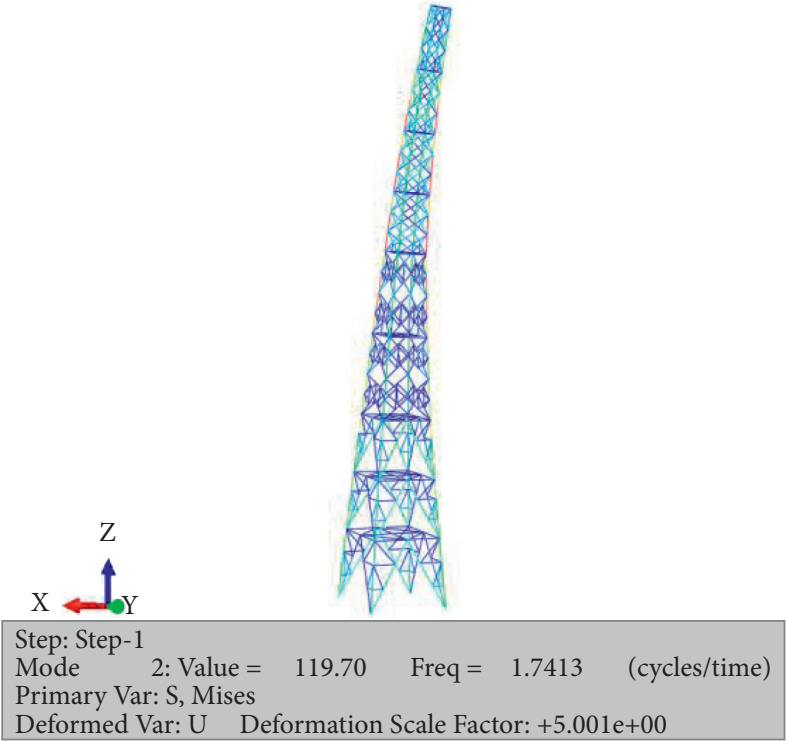

(b)

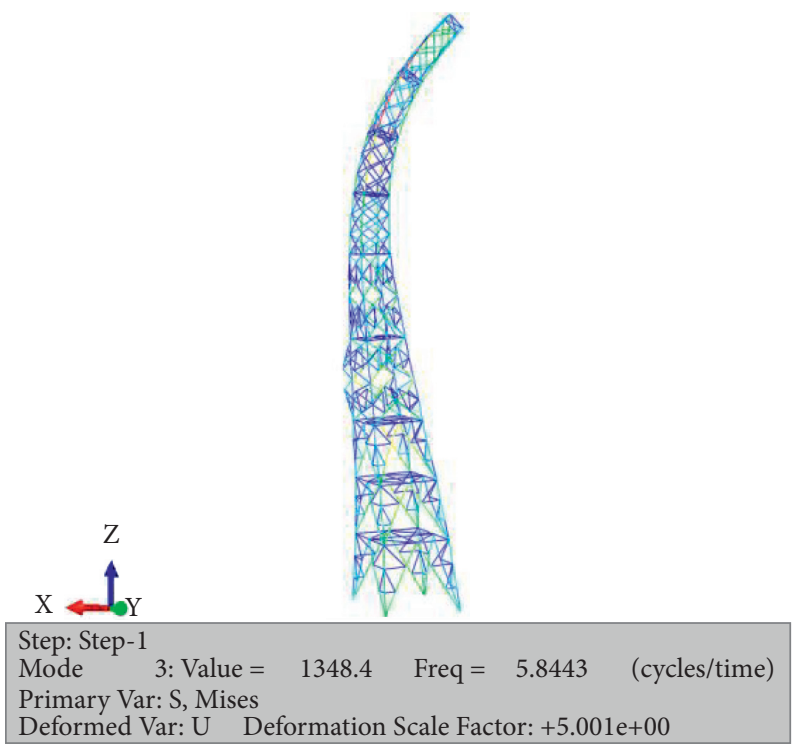

(c)

Figure 2: Mode shapes of (a) first order, (b) second order, and (c) third order. 


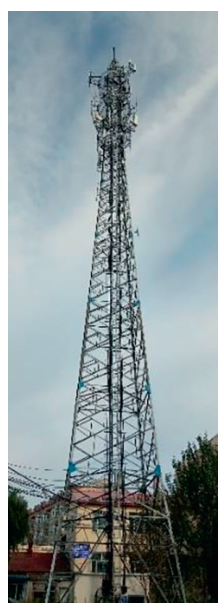

(a)

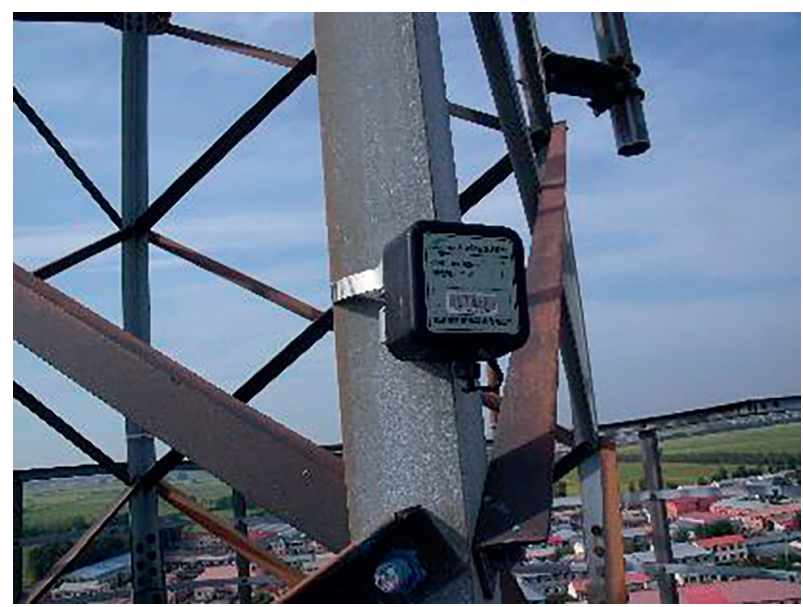

(b)

Figure 3: Measured real (a) angle steel and (b) example of the installed three-directional acceleration transducers used for the measurements.

TABLE 5: Comparison of the natural periods between the model and the prototype structure.

\begin{tabular}{lcccc}
\hline & \multicolumn{2}{c}{$\mathrm{X}$} & \multicolumn{2}{c}{$\mathrm{Y}$} \\
& $\mathrm{F}(\mathrm{Hz})$ & $T_{1}(\mathrm{~s})$ & $f(\mathrm{~Hz})$ & $T_{1}(\mathrm{~s})$ \\
\hline Prototype tower & 1.51 & 0.66 & 1.50 & 0.67 \\
FE model & 1.74 & 0.57 & 1.74 & 0.57 \\
Difference & - & $13.6 \%$ & - & $14.9 \%$ \\
\hline
\end{tabular}

Therefore, the acceleration amplification factor (AAF) at the top of the tower is a critical structural dynamic response demand parameter. Therefore, in this study, MRD and AAF were assigned as EDP. The structural response to the communication tower under the action of pulse-like ground motions and ordinary ground motions along the $X$ direction is listed in Table 6.

\section{Evaluation of IM}

5.1. Results in Terms of Efficiency. The efficiency of intensity measures reveals that under a certain ground motion intensity condition, the discrete engineering structure requires small parameters. On the premise of not lowering the calculation accuracy, the estimated conditional probability $P(E D P \mid I t M)$ can be reduced, and the number of seismic records and dynamic time history analysis conditions required for analysis can be reduced to a certain extent. Typically, the validity of ground motion parameters is determined by conditional logarithmic standard deviation $\beta$ to judge, and efficiency is the core index used to measure the superiority over an $\mathrm{IM}_{\mathrm{i}}[19]$.

The relationship between the EDP and $\mathrm{IM}_{\mathrm{i}}$ approximately satisfies the logarithmic relationship, and its relationship formula is displayed as follows:

$$
\ln (\mathrm{EDP})=\ln (a)+b \cdot \ln \left(I M_{i}\right) .
$$

The aforementioned formula satisfies the univariate linear regression model, and the least square principle can be used to perform regression analysis on the obtained $n$ scatter points $\left(\mathrm{IM}_{\mathrm{i}}, \mathrm{EDP}_{\mathrm{i}}\right)$ to obtain the empirical regression lines of $\ln \left(\mathrm{IM}_{\mathrm{i}}\right)$ and $\ln (\mathrm{EDP})$ and obtain the conditional logarithmic standard deviation, as follows.

$$
\beta_{\ln \left(\operatorname{EDP} \mid I M_{i}\right)}=\sqrt{\frac{\sum\left(\ln (\mathrm{EDP})-\ln \left(a \cdot I M_{i}^{b}\right)\right)^{2}}{n-2}} .
$$

For any intensity measure $I M_{\mathrm{i}}$, the smaller the conditional logarithmic standard deviation, $\beta_{\ln \left(\mathrm{EDP} \mid I M_{i}\right)}$, is the smaller the discrete type of seismic response to engineering structure is, indicating that the efficiency of the ground motion parameter $\mathrm{IM}_{\mathrm{i}}$ is higher, otherwise, the efficiency is lower.

Under the action of pulse-like ground motions and ordinary ground motions, the conditional logarithmic standard deviation, $\beta_{\ln \left(E D P \mid I t M_{\mathrm{i}}\right)}$, corresponding to the intensity measures to be analysed, and the structural dynamic response (MRD and AAF) was calculated by using the cloud analysis method, as displayed in Figure 4.

(1) For MRD and AAF, the conditional logarithmic standard deviation $\beta_{\ln \left(E D P \mid I t M_{i}\right)}$ of spectrum parameters is the smallest, that is, among the four aforementioned four ground motion intensity parameters, spectrum parameters are the most effective.

(2) Figure 4(a) reveals for the MRD, under the action of pulse-like ground motions and ordinary ground motions, with the exception that the conditional logarithmic standard deviation $\beta_{\ln \left(E D P \mid I t M_{i}\right)}$ corresponding to $\mathrm{Sa}\left(T_{1}\right)$ is basically equal, the values of other intensity measures corresponding to pulse-like ground motions are smaller. The MRD are predicted more efficiently with pulse-like ground motions than with ordinary motions, that is, regression models are better fitted to data from the pulse-like ground motion set than to that from ordinary sets. 
TABLE 6: Structural responses to pulse-like GMs and ordinary GMs.

\begin{tabular}{|c|c|c|c|c|c|}
\hline \multicolumn{3}{|c|}{ Pulse-like GMs } & \multicolumn{3}{|c|}{ Ordinary GMs } \\
\hline Sequence & $\operatorname{MRD}(\mathrm{mm})$ & AAF & No. & $\operatorname{MRD}(\mathrm{mm})$ & $\mathrm{AAF}$ \\
\hline PL1 & 50 & 4.13 & OR1 & 20 & 8.63 \\
\hline PL2 & 30 & 2.81 & OR 2 & 20 & 9.47 \\
\hline PL3 & 78 & 4.89 & OR3 & 70 & 13.71 \\
\hline PL4 & 43 & 4.65 & OR4 & 40 & 15.87 \\
\hline PL5 & 110 & 7.80 & OR5 & 60 & 8.71 \\
\hline PL6 & 72 & 5.71 & OR6 & 3 & 8.64 \\
\hline PL7 & 210 & 4.79 & OR7 & 14 & 5.56 \\
\hline PL8 & 160 & 6.89 & OR8 & 1 & 5.88 \\
\hline PL9 & 380 & 10.14 & OR9 & 1 & 7.11 \\
\hline PL10 & 110 & 8.10 & OR10 & 1 & 7.38 \\
\hline PL11 & 270 & 4.04 & OR11 & 7 & 10.36 \\
\hline PL12 & 160 & 6.20 & OR12 & 5 & 8.06 \\
\hline PL13 & 140 & 5.77 & OR13 & 25 & 8.82 \\
\hline PL14 & 150 & 6.14 & OR14 & 30 & 10.91 \\
\hline PL15 & 70 & 4.74 & OR15 & 22 & 12.64 \\
\hline PL16 & 130 & 6.24 & OR16 & 11 & 8.82 \\
\hline PL17 & 500 & 14.32 & OR17 & 30 & 7.68 \\
\hline PL18 & 160 & 7.79 & OR18 & 20 & 9.13 \\
\hline PL19 & 170 & 8.19 & OR19 & 10 & 8.16 \\
\hline PL20 & 270 & 10.76 & OR20 & 8 & 7.30 \\
\hline PL21 & 80 & 5.25 & OR21 & 15 & 13.75 \\
\hline PL22 & 110 & 5.77 & OR22 & 20 & 6.64 \\
\hline PL23 & 220 & 6.40 & OR23 & 3 & 3.87 \\
\hline PL24 & 150 & 6.66 & OR24 & 20 & 10.09 \\
\hline PL25 & 120 & 2.91 & OR25 & 43 & 9.37 \\
\hline PL26 & 320 & 5.63 & OR26 & 5 & 6.00 \\
\hline PL27 & 210 & 8.88 & OR27 & 16 & 9.42 \\
\hline PL28 & 100 & 6.26 & OR28 & 20 & 8.09 \\
\hline PL29 & 180 & 5.57 & OR29 & 46 & 11.51 \\
\hline PL30 & 390 & 6.19 & OR30 & 18 & 13.29 \\
\hline PL31 & 100 & 6.54 & OR31 & 10 & 10.94 \\
\hline PL32 & 140 & 7.58 & OR32 & 6 & 8.93 \\
\hline PL33 & 80 & 6.91 & OR33 & 15 & 10.46 \\
\hline PL34 & 250 & 5.88 & OR34 & 16 & 9.87 \\
\hline PL35 & 110 & 5.06 & OR35 & 16 & 10.46 \\
\hline PL36 & 80 & 7.07 & OR36 & 24 & 13.82 \\
\hline PL37 & 190 & 9.15 & OR37 & 120 & 4.75 \\
\hline PL38 & 250 & 7.56 & OR38 & 20 & 10.41 \\
\hline PL39 & 200 & 5.67 & OR39 & 9 & 4.79 \\
\hline PL40 & 50 & 4.93 & OR40 & 16 & 9.60 \\
\hline PL41 & 140 & 12.22 & OR41 & 22 & 9.02 \\
\hline PL42 & 70 & 5.58 & OR42 & 4 & 5.57 \\
\hline PL43 & 80 & 7.45 & OR43 & 16 & 8.50 \\
\hline PL44 & 150 & 7.94 & OR44 & 3 & 5.21 \\
\hline PL45 & 130 & 6.81 & OR45 & 20 & 6.14 \\
\hline PL46 & 40 & 4.13 & OR46 & 23 & 7.53 \\
\hline PL47 & 90 & 5.91 & OR47 & 40 & 12.10 \\
\hline PL48 & 150 & 7.65 & OR48 & 5 & 6.81 \\
\hline PL49 & 100 & 7.05 & OR49 & 2 & 4.75 \\
\hline PL50 & 140 & 8.99 & OR50 & 8 & 4.30 \\
\hline
\end{tabular}

(3) Figure 4(b) reveals that for the AAF, $\beta_{\ln \left(E D P \mid I M_{i}\right)}$ corresponding to the duration parameters $\left(U_{\mathrm{du}}\right.$ and $S_{\mathrm{du}}$ ) and CAV in the energy parameters under the action of pulse ground motion is significantly less than that under the action of ordinary ground motion, while the values of $\beta_{\ln \left(E D P \mid I M_{i}\right)}$ corresponding to other ground motion parameters are close under the action of pulse-like ground motions and ordinary ground motions.

(4) The aforementioned results revealed that for MRD and $\mathrm{AAF}$, the discrete type of ground motion parameters considered in this study were less than that under ordinary ground motion. From the perspective of efficiency, the top-five most effective intensity measures are amplitude parameter PGA, spectrum parameters $\mathrm{Sa}\left(T_{1}\right)$ and EPA, and energy parameters CAV and CAVs. The logarithmic standard deviation $\beta_{\ln \left(\mathrm{EDP} \mid I M_{i}\right)}$ from duration parameter conditions is higher than 0.5 , representing large discrete and unreliable intensity measures.

5.2. Results in Terms of Practicality. Practicality refers to whether a direct correlation exists between an IM and the engineering demand placed on the structure. For a specified intensity measure, the practicability is not strong, which indicates that the seismic response to the engineering structure is slightly influenced by the change in this parameter. The quantitative index of practicability can be assessed by using linear regression coefficient $b$ given in (1). The larger the value of $b$ is, the greater the influence of the change of intensity measures on the seismic response to engineering structures is, that is, the stronger the correlation is, the higher the practicability is; if the value of $b$ is close to 0 , the change in intensity measures does not affect the seismic response to engineering structures [20]. An example of the relative practicality of intensity measures is displayed in Figure 5.

The regression coefficient $b$ corresponding to various intensity measures can be derived by fitting the straight line of (1), as displayed in Figure 6. For intensity measures, the requirements of efficiency and practicability must be simultaneously met; therefore, only the practicability of the five most effective ground motion parameters evaluated in the previous step can be compared. The practicability of the selected intensity measures under the action of pulse-like ground motions is stronger than that under the action of ordinary ground motions. For the spectrum parameters EPA and $\mathrm{Sa}\left(T_{1}\right)$, the regression coefficient $b$ corresponding to $\mathrm{Sa}\left(T_{1}\right)$ is larger. Thus, the practicability of $\mathrm{Sa}\left(T_{1}\right)$ is stronger than EPA. This result reveals that $\mathrm{Sa}\left(T_{1}\right)$ related to the vibration characteristics of the structure is more sensitive to the structural demand parameters than EPA. Furthermore, according to Figure 6(a) and 6(b), the regression coefficient $b$ corresponding to CAVs under ordinary ground motion is close to 0 , indicating poor practicability, that is, there is small or no dependence of the level of engineering demand on the CAV level. Typically, the amplitude parameter PGA, spectrum parameter $\mathrm{Sa}\left(T_{1}\right)$, and energy parameter $\mathrm{CAV}$ are highly practical.

5.3. Results in Terms of Sufficiency. Sufficiency is a crucial index to assess the independence of the ground motion parameter and indicates the correlation between the ground motion parameter $\left(\mathrm{IM}_{\mathrm{i}}\right)$ and ground motion information parameter (magnitude $M$ or source-to-site distance $\mathrm{R}$ ). A 


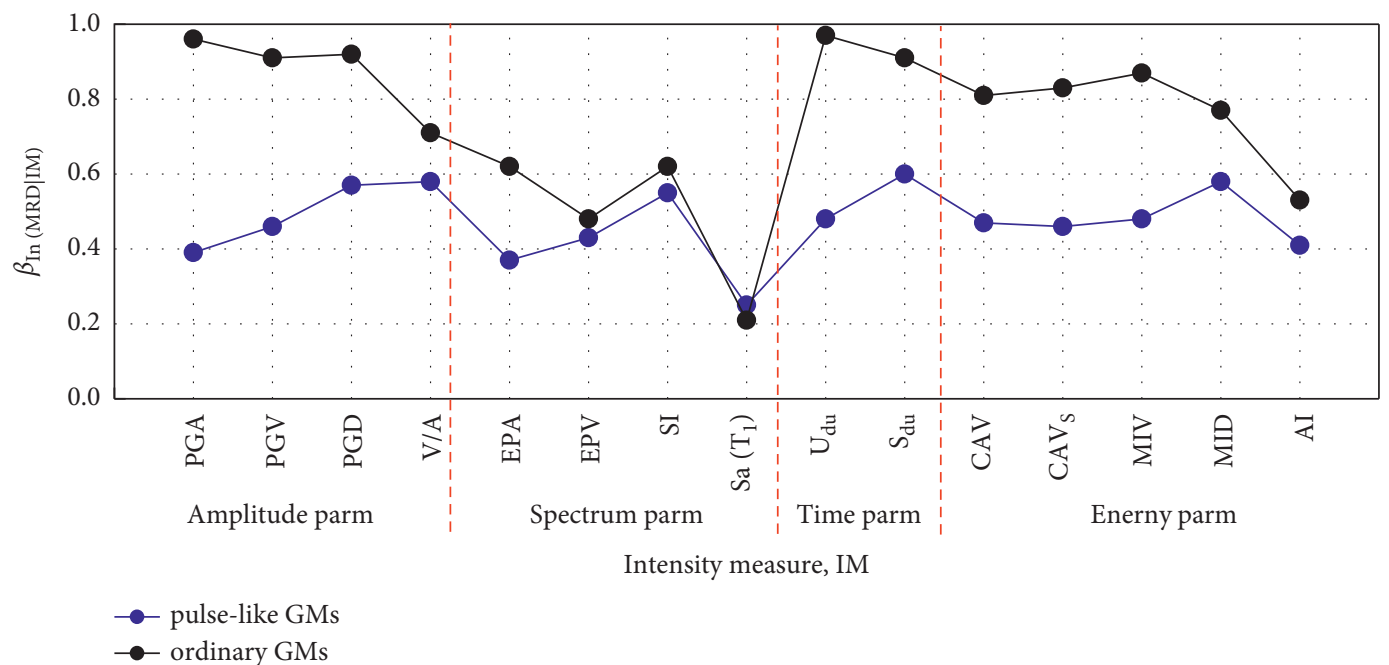

(a)

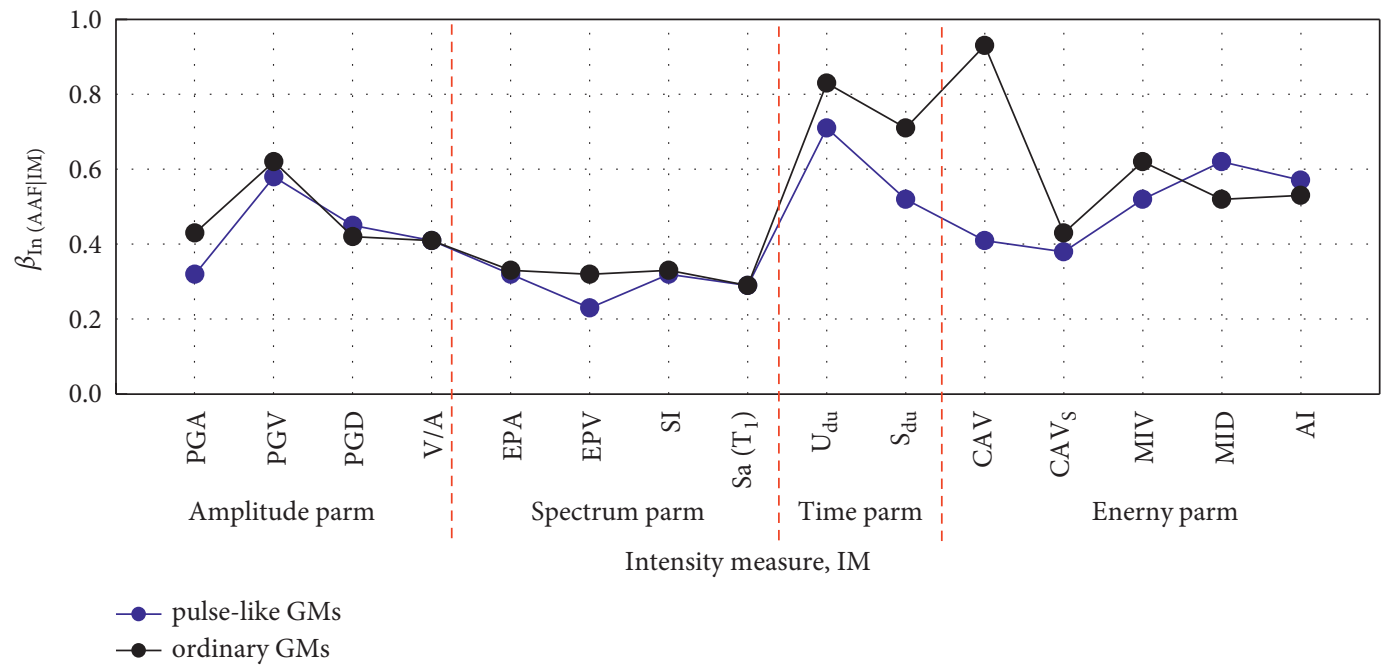

(b)

FIGURE 4: Reveals the following: (a) MRD and (b) AAF, obtained from the cloud analysis subjected to pulse-like and ordinary ground motions.

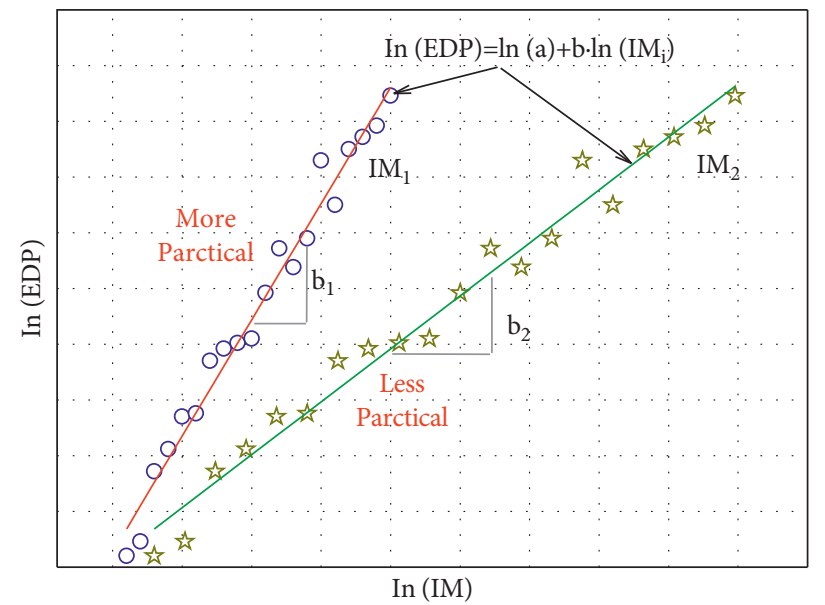

Figure 5: Example of the relative practicality of intensity measures. 


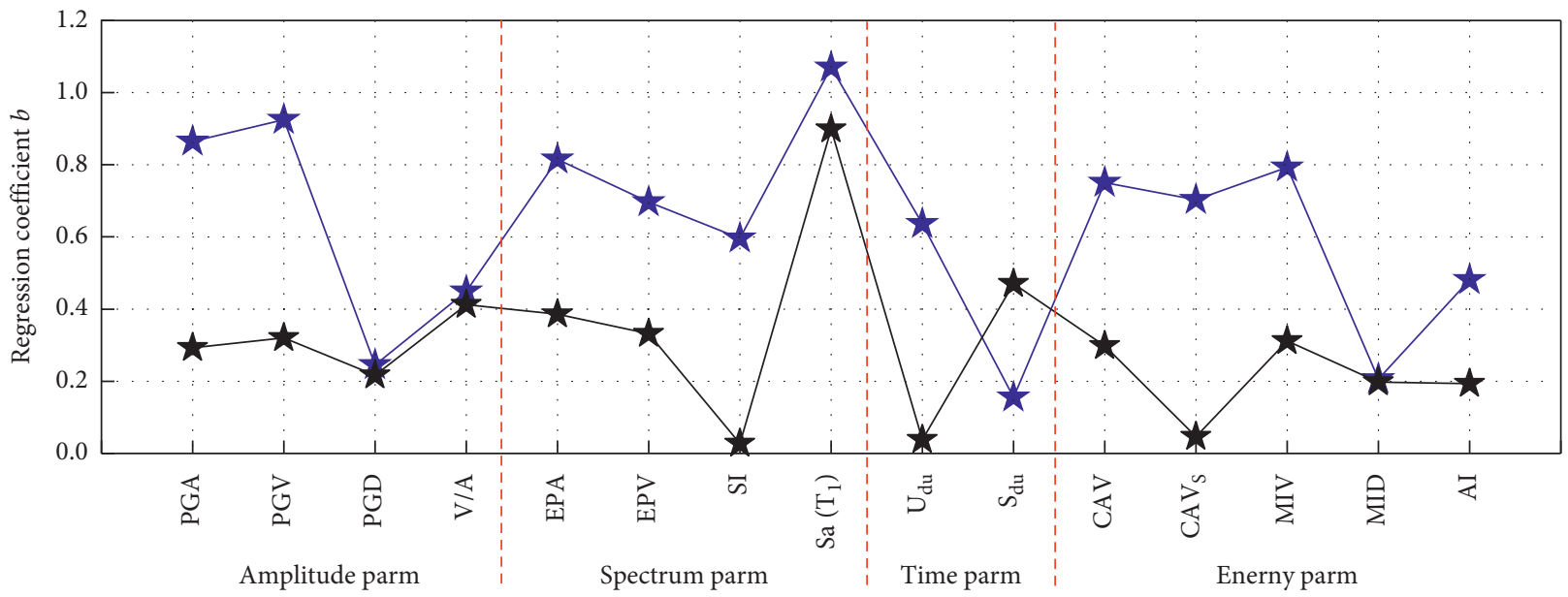

Intensity measure, IM

(a)

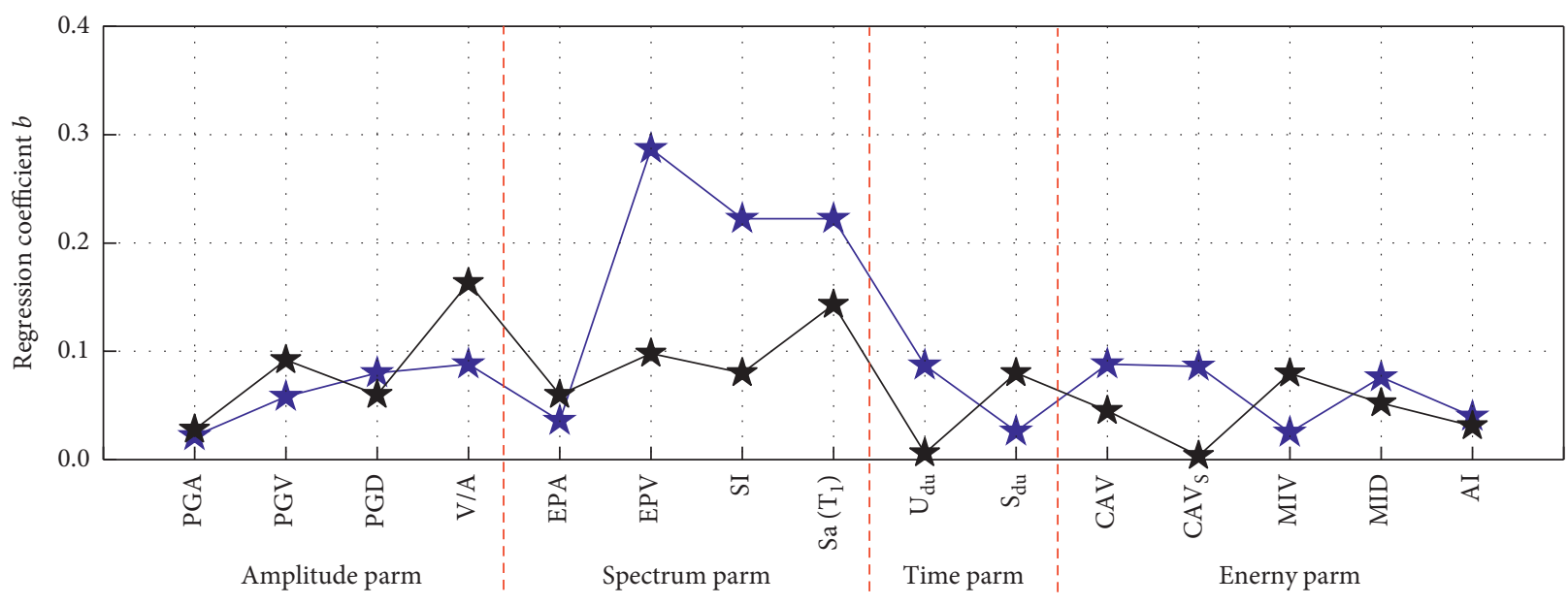

Intensity measure, IM

(b)

FIGURE 6: Regression coefficient, $b$, corresponding to the engineering demanded parameters (a) MRD and (b) AAF, obtained from the cloud analysis subjected to pulse-like and ordinary ground motions.

sufficient ground motion parameter should be statistically independent of the ground motion information parameter. If the demand residuals and seismic information parameters are not statistically independent of each other, the $p$ value of regression analysis would be less than the given significance level, indicating that the sufficiency of $\mathrm{IM}_{\mathrm{i}}$ is poor. The $p$ value of 0.05 was considered the cutoff for an insufficient IMi. If the $p$ value value is larger, the sufficiency of IM would be stronger [21]. Because of the limitations on the length of the article, only the scatter and fitting line expressions of the required residual of AAF and magnitude $M$ when PGA is a ground motion parameter are presented in Figure 7.

The $p$ values derived from the three highly practical intensity measures PGA, $S a\left(T_{1}\right)$, and $\mathrm{CAV}$ for the seismic magnitude and source-to-site distance F-text are displayed in Figure 8. The results reveal that under the action of ordinary ground motions, the $p$ value among PGA, CAV, and magnitude $M$ is equal to 0 , indicating a complete linear correlation and sufficiency is 0 . If PGA or CAV is taken as IM to select the ground motions for the dynamic time history analysis of the floor four-leg angle steeled communication tower, the results are strongly related to the magnitude of the earthquake event. Under the action of pulse-like ground motions, the $p$ value between PGA and source-to-site distance $R$ is equal to 0 , demonstrating complete linear correlation. Only the correlation coefficient $p$ value between the spectrum parameter $\mathrm{Sa}\left(T_{1}\right)$ and the magnitude $M$ or source-to-site distance $R$ is greater than the 


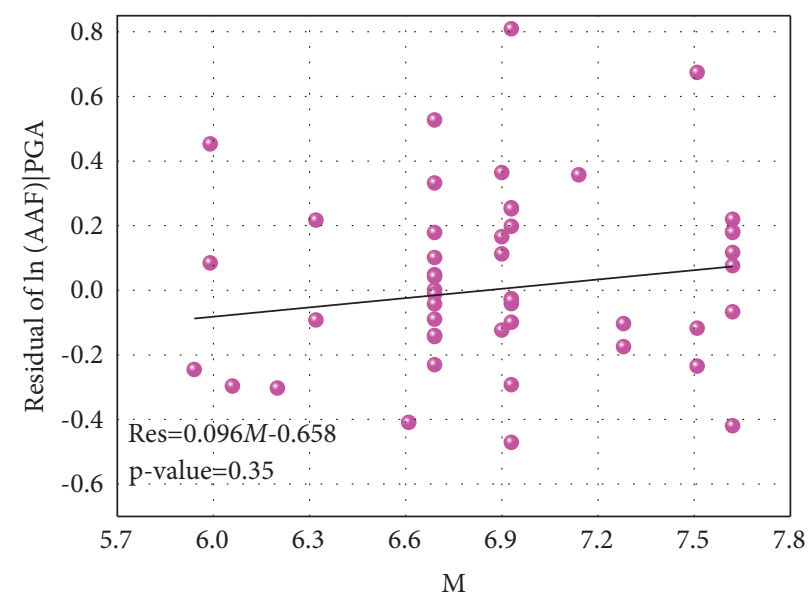

FIgURE 7: Testing the sufficiency of PGA with respect to $M$ for predicting AAF.

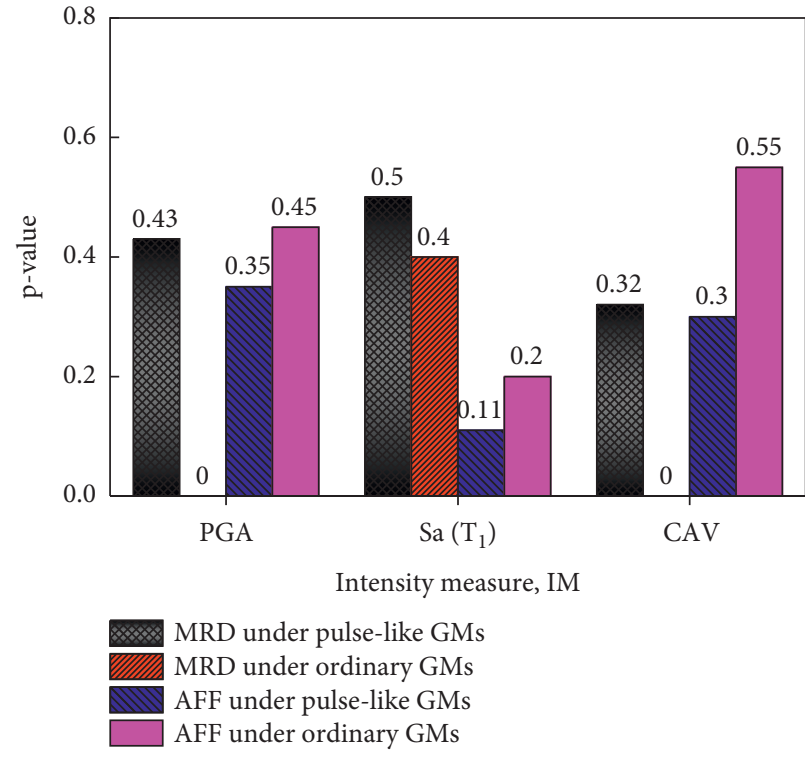

(a)

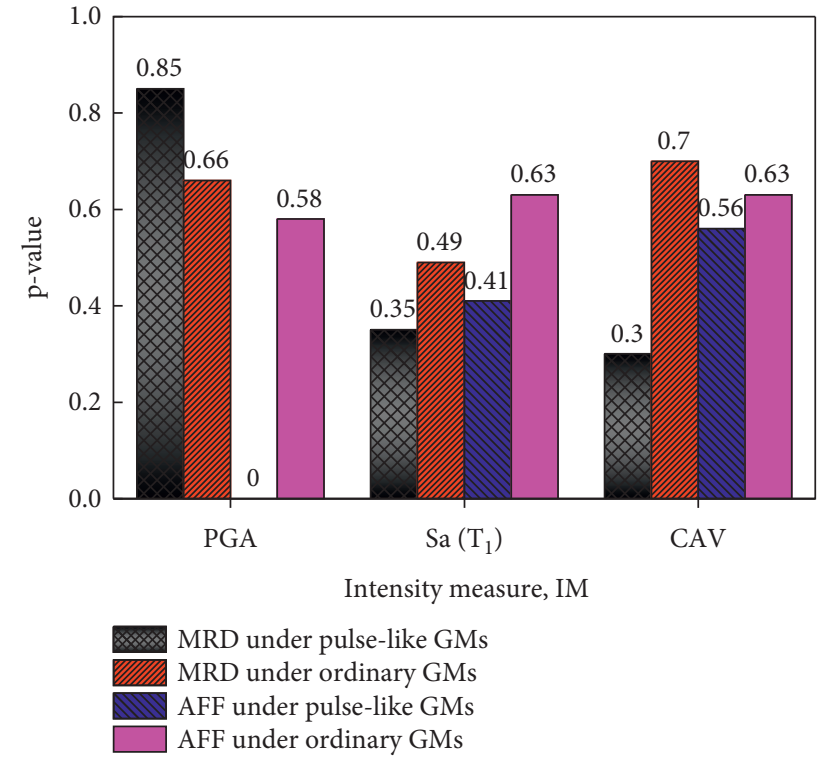

(b)

FIgURE 8: Median $p$ values obtained from investigating the sufficiency of typical IMi with respect to (a) magnitude and (b) source-to-site distance.

given significance level of 0.05 under the action of pulse-like ground motions or ordinary ground motions, that is, it satisfies the sufficiency requirements.

Briefly, for the lattice tower such as the communication tower, irrespective of whether under the action of pulse-like and ordinary ground motions, the most suitable intensity measure is the spectral acceleration $\mathrm{Sa}\left(T_{1}\right)$ corresponding to the natural period of the structure from the three aspects of efficiency, practicability, and sufficiency.

\section{Conclusions}

In this study, a standard floor four-leg angle steel communication tower was considered. Based on the cloud analysis method, a linear logarithmic regression fitting method of intensity measures, considering the uncertainty of input ground motion, the optimal intensity measures under pulse-like ground motions, and ordinary ground motions, was determined from the perspectives of efficiency, practicability, and sufficiency.

(1) For MRD and AAF, the discrete type of ground motion parameters considered in this study is less than that under the action of impulse ground motion. From the perspective of efficiency, the top-five most effective intensity measures are amplitude parameter PGA, spectrum parameter $\mathrm{Sa}\left(T_{1}\right)$ and EPA, and energy parameter CAV and CAVs. The duration parameters are discrete and noneffective intensity measures.

(2) Under the action of pulse ground motion, the practicability of the selected intensity measures is stronger than that of ordinary ground motion. For the spectrum parameters EPA and $\mathrm{Sa}\left(T_{1}\right), \mathrm{Sa}\left(T_{1}\right)$ is 
more practical than EPA. Furthermore, the regression coefficient $b$ corresponding to CAVs under ordinary ground motion is close to 0 , indicating that the practicability is considerably poor. Typically, the amplitude parameter PGA, spectrum parameter $\mathrm{Sa}\left(T_{1}\right)$, and energy parameter $\mathrm{CAV}$ are highly practical.

(3) For the lattice tower, such as the communication tower, irrespective of whether the measure is under the action of pulse-like ground motion or ordinary ground motion, considering from the three aspects of efficiency, practicability, and sufficiency, the most suitable intensity measure is the spectral acceleration $\mathrm{Sa}\left(T_{1}\right)$ corresponding to the natural period of the structure.

The scalar intensity measures are considered in this study. In a subsequent study, the vector intensity measures can be elaborated.

\section{Data Availability}

The data used to support the findings of this study are available from the corresponding author upon request.

\section{Conflicts of Interest}

The authors declare that they have no conflicts of interest.

\section{Acknowledgments}

The authors gratefully acknowledge the financial support provided by the Scientific Research Fund of Institute of Engineering Mechanics, China Earthquake Administration (Grant nos. 2020EEEVL0503 and 2019EEEVL0304) and scientific research fund project of Binzhou University (Grant no. BZXYLG2102).

\section{References}

[1] L. Tian, X. Zhang, and X. Fu, "Collapse simulations of communication tower subjected to wind loads using dynamic explicit method," Journal of Performance of Constructed Facilities, vol. 34, no. 3, 2020.

[2] X. Fu, H.-N. Li, L. Tian, J. Wang, and H. Cheng, "Fragility analysis of transmission line subjected to wind loading," Journal of Performance of Constructed Facilities, vol. 33, no. 4, 2019.

[3] Z. Meng, G. F Zhao, L. L Wang, and J. Li, "Wind-induced coupling vibration effects of high-voltage transmission towerline systems," Shock and Vibration, vol. 2017, Article ID 1205976, 34 pages, 2017.

[4] X. Wang, "Thoughts left by the 311 earthquake in Japan," City and disaster reduction, vol. 2017, no. 5, pp. 31-35, 2017, (Chinese).

[5] A. W. Liu, S. Xia, H. S. Lv, K. Chen, and W. J. Xu, “Typical damage analysis for mobile communication base stations in the extremely damage area of Wenchuan earthquake," Telecom Engineering Technics and Standardization, vol. 25, no. 12, pp. 82-86, 2012, (Chinese).

[6] H. Pan, C. Li, and L. Tian, "Seismic fragility analysis of transmission towers considering effects of soil-structure interaction and depth-varying ground motion inputs," Bulletin of Earthquake Engineering, vol. 19, no. 11, pp. 4311-4337, 2021.

[7] M. Sadeghi, F. Mohajeri, and E. Khalaghi, "Seismic performance and communication failure of cell phone towers in Iran's seismic zones, case study: developing structural and communicational fragility curves for $24 \mathrm{M}$ monopole tower," in Proceedings of the 7th International Conference on Urban Earthquake Engineering (7CUEE) \&5th International Conference on Earthquake Engineering (5ICEE), Tokyo Institute of Technology, Tokyo, Japan, March 2010.

[8] L. Tian, X. Gai, and B. Qu, "Shake table tests of steel towers supporting extremely long-span electricity transmission lines under spatially correlated ground motions," Engineering Structures, vol. 132, pp. 791-807, 2017.

[9] L. Tian, R. Ma, and B. Qu, "Influence of different criteria for selecting ground motions compatible with IEEE 693 required response spectrum on seismic performance assessment of electricity transmission towers," Engineering Structures, vol. 156, pp. 337-350, 2018.

[10] G. G. Amiri and S. R. Massah, "Seismic response to4-legged self-supporting telecommunication tower," IJE Transactions B: Applications, vol. 20, no. 2, pp. 107-126, 2007.

[11] M. A. Khedr and G. McClure, "A simplified method for seismic analysis of lattice telecommunication towers," Canadian Journal of Civil Engineering, vol. 27, no. 3, pp. 533-542, 2000.

[12] N. Luco and C. A. Cornell, "Structure-specific scalar intensity measures for near-source and ordinary earthquake ground motions," Earthquake Spectra, vol. 23, no. 2, pp. 357-392, 2007.

[13] J. W. Baker, Vector-valued Ground Motion Intensity Measures for Probabilistic Seismic Demand Analysis [D], Stanford University, California, 2006.

[14] Q. H. Lai, J. J. Hu, L. L. Xie, J. Y. Tan, and Z. F. Zhao, "Correlation analysis potential damage parameters of pulselike ground motion," World Earthquake Engineering, vol. 36, no. 1, pp. 35-43, 2020, (Chinese).

[15] C. Zhai, C. Li, S. Kunnath, and W. Wen, "An efficient algorithm for identifying pulse-like ground motions based on significant velocity half-cycles," Earthquake Engineering \& Structural Dynamics, vol. 47, no. 3, pp. 757-771, 2018.

[16] F. Jalayer and C. A. Cornell, A Technical Framework for Probability-Based Demand and Capacity Factor Design (DCFD) Seismic Formats, Pacific Earthquake Engineering Center (PEER), California, USA, 2003.

[17] F. Jalayer, R. De Risi, and G. Manfredi, "Bayesian cloud analysis: efficient structural fragility assessment using linear regression," Bulletin of Earthquake Engineering, vol. 13, no. 4, pp. 1183-1203, 2015.

[18] A. K. Kazantzi and D. Vamvatsikos, "Intensity measure selection for vulnerability studies of building classes," Earthquake Engineering \& Structural Dynamics, vol. 44, no. 15, pp. 2677-2694, 2015.

[19] E. Hossein, J. Fatemeh, L. Andrea, M. Fabrizio, and M. Gaetano, "Preliminary ranking of alternative scalar and vector intensity measures of ground shaking," Bulletin of Earthquake Engineering, vol. 13, pp. 2805-2840, 2015.

[20] J. E. Padgett, B. G. Nielson, and R. DesRoches, "Selection of optimal intensity measures in probabilistic seismic demand models of highway bridge portfolios," Earthquake Engineering \& Structural Dynamics, vol. 37, no. 5, pp. 711-725, 2008.

[21] M. Yakhchalian and G. Ghodrati Amiri, "A vector intensity measure to reliably predict maximum drift in low- to mid-rise buildings," Proceedings of the Institution of Civil Engineers Structures and Buildings, vol. 172, no. 1, pp. 42-54, 2019. 